\section{Science studies misjudged?}

Sir - Gottfried and Wilson ${ }^{1}$ remark critically that "SSK [ sociology of scientific knowledge] accounts often treat only the earliest phases of a scientific development, when the evidence is uncertain, and largely ignore subsequent convincing confirmations". This is true of controversy studies in SSK, but not of one of the books at issue, my own Constructing Quarks ${ }^{2}$. There I documented and analysed the history of the establishment of the standard model as the 'new orthodoxy' in elementary particle physics.

Ellis ${ }^{3}$ makes a similar mistake, and adds that he would "also like [me] to document and compare more thoroughly the rejection by the scientific community of false 'discoveries'". I have published essays on discredited 'discoveries' of magnetic monopoles and isolated quarks, and on the ultimately unsuccessful theoretical arguments that the new particles (the J/psi and so on) were manifestations of quark colour rather than charm (see, for example, ref. 4). The analysis in those essays goes along the same lines as that of Constructing Quarks, and if Ellis wants to dispute it, I will be happy to respond.
Capasso ${ }^{5}$ is mistaken in asserting that successful technology "validates the specific theories on which it is founded". A machine works because it works, not because of what anybody thinks about it ${ }^{6}$. And, as I believe Gottfried and Wilson recognize, Capasso's idea that technology owes everything to prior science is as historically misleading as its inverse. In short, the continuing criticism of science studies in your pages remains wide of its mark.

\section{Andrew Pickering}

Department of Sociology,

University of Illinois

at Urbana-Champaign,

Urbana, IL 61801, USA

e-mail:pickerin@uiuc.edu

1. Gottfried, K. \& Wilson, K. Nature 387, 545-546 (1997)

2. Pickering, A. Constructing Quarks: A Sociological History of Particle Physics (Univ. Chicago Press, 1984).

3. Ellis, J. Nature 388, 13 (1997).

4. Pickering, A. Isis 72, 216-236 (1981).

5. Capasso, F. Nature 387, 544-545 (1997)

6. Pickering, A. The Mangle of Practice: Time, Agency, and Science (Chicago Univ. Press, 1995).

\section{Narrowness in science}

Sir - I agree wholeheartedly with Mott T. Greene's assessment of narrowness in science (Nature 388, 619-620; 1997). However, the narrowness goes much deeper than Greene implies. For example, my own research area stretches from condensedmatter physics to physical chemistry, both theory and experiment. These interests are very broad by modern standards, but would probably still be classed as narrow by Greene.

Some of this narrowness has been brought on by the twentieth-century growth of science itself. In the nineteenth century, so little was known that scientific minds could comfortably stretch from medicine to astronomy. However, in addition to the scientific growth during the past half-century, science funding policies in the United States and elsewhere have provoked narrowness through the absurd and self-destructive 'anonymous peerreview' system. So-called peer reviewers feel that outsiders cannot know enough to contribute to their field. They thus tend to vote down financial support of any scientist who would like to broaden out, and thus encroach on the reviewer's territory.

These trends have resulted in small knots of hostile specialists in evernarrowing research areas. When a physical chemist is asked what field he or she is in, the usual answer nowadays is "infrared spectroscopy" or "NMR" or "statistical mechanics" or "quantum mechanics", when the answer should be "Right at the moment, I am working on such and such a problem using a variety of these research tools". 
It is like asking a carpenter what his field is and getting the reply, "hammer" or "saw" or "screwdriver". But what do you build? What do you create? Even if such questions did occur to scientists, the problem to be solved would require such a wide variety of techniques and encroach on so many areas of specialization that, through the peerreview system, it could never be funded.

This means unfortunately that anyone with Greene's "generalized curiosity” is now unable to prosper in science. In the near future, those who go in and stay in will mainly be those with such limited thinking ability that nothing scientifically really new will ever be discovered. Is that what everyone wants?

\section{G. Wilse Robinson}

Department of Chemistry and Biochemistry,

Texas Tech University,

Lubbock, Texas 79409-1061, USA

e-mail:gwrob@ttacs.ttu.edu

Sir - I disagree with Greene's main conclusions. In my opinion, the main impediment in discussing areas of research other than our own is the knowledge that we do not know enough. While I am giving classes about CD4-gp120 interactions and CCR5/CXCR4 discrimination of HIV tropism, new receptors are being described and my knowledge seems completely outdated.
The 'information network' is so immense that we do not have time to read all about our narrow specialities, much less related areas, and still do our own research. And the pressure to publish is still increasing, the number of reviews published appears to me to be decreasing, and my ignorance of results from other areas of research stupefying.

Working in research I do not like being 'outdated' or simply wrong, so I avoid public statement of opinions.

\section{Vera Bongertz}

Lab AIDS \& Molecular Immunology,

Oswaldo Cruz Foundation,

Rio de Janeiro, RJ, Brazil

e-mail:bongertz@gene.dbbm.fiocruz.br

\section{Duplications in nomenclature}

Sir — The nomenclature of genes and proteins in molecular and developmental biology, as discussed in a recent leading article in Nature ${ }^{1}$, is often illogical and confusing. This problem is sometimes compounded when two proteins without any structural and functional relationship receive the same designation.

In a recent publication by Pan et al. ${ }^{2}$, for example, the authors describe the cloning and characterization of a new membrane-anchored chemokine and propose the name "neurotactin" for this type of molecule.

The term "neurotactin" was, however, used previously to describe a Drosophila membrane protein with an extracellular serine esterase-type protein domain which is dynamically expressed by neuroblasts and other tissues in the fly embryo ${ }^{3,4}$. Drosophila neurotactin has no sequence or functional similarity to the molecule characterized by Pan et al. ${ }^{2}$.

As a solution to such problems, journals should require the authors of manuscripts in which new names or terms are proposed to carry out a computer literature search.

In the case described above, a Medline search would have revealed the duplication and avoided possible confusion to some readers. Luckily, the CX3C membranebound chemokine described by Pan et al. ${ }^{2}$ is identical to a molecule for which Bazan et al. ${ }^{5}$ proposed the name "fractalkline", so an alternative designation is available.

\section{Michael Hortsch}

Department of Anatomy and Cell Biology, University of Michigan,

Ann Arbor, Michigan 48109-0616, USA

e-mail:hortsch@umich.edu 1. Nature 389, 1 (1997).

2. Pan, Y. et al. Nature 387, 611-617 (1997).

3. Hortsch, M. et al. Development 110, 1327-1340 (1990).

4. De La Escalera, S. et al. EMBO J. 9, 3593-3601 (1990).

5. Bazan, J. F. et al. Nature 385, 640-644 (1997). 